Erilane de Castro Lima 1

Tânia Lucia Montenegro Stamford 1

1 Departamento de Nutrição, UFPE. Av. Professor Moraes Rego, $1235,50670-420$, Recife PE.

erilane@ig.com.br

\section{Cryptosporidium spp. no ambiente aquático: aspectos relevantes da disseminação e diagnóstico}

\author{
Cryptosporidium spp. in aquatic environment: \\ the principal aspects of dissemination \\ and diagnostic methods
}

Abstract Criptosporidiosis is an important problem of public health. The role of Cryptosporidium parvum as a waterborne pathogen has been documented. But epidemiological features of this parasitic protozoon lead to the assumption that the incidence of Cryptosporidium spp. in aquatic environmental is underestimated. The lack of sensitive detection methods adapted for oocysts detection in water contributed to this under-reporting. This review paper discusses the theme, including the occurrence of these pathogens in aquatic environmental and the available detection methods. Although the molecular biology technique used for identification of the agent, the parasitological diagnostics' method continue to show satisfactory results. Polimerase chain reaction (PCR) is a promising detection method and the potencial use in the detection of $\mathrm{C}$. parvum in water has been described. The Cryptosporidium spp. oocysts identification in water samples depends on the number of oocysts, sensibilty of methods, and the concentration technique and this step is fundamentally to precision of test.

Key words Cryptosporidium spp., Waterborne transmission, Diagnostic methods, Concentration of oocysts
Resumo A criptosporidiose é uma doença de importância para a saúde pública. A via de transmissão do Cryptosporidium parvum é associada freqüentemente à contaminação de água. Porém, estudos epidemiológicos revelam que sua incidência no ambiente aquático é subestimada. A falta de método apropriado de detecção para a pesquisa dos oocistos em amostras de água contribui para isso. $O$ artigo discute vários aspectos do tema, dentre eles, a ocorrência desse patógeno no ambiente aquático e os avanços nos métodos de detecção. Apesar da existência de técnicas de biologia molecular para a identificação do agente, métodos parasitológicos ainda apresentam resultados satisfatórios. A reação em cadeia de polimerase (PCR) é um método de detecção promissor. A identificação dos oocistos de Cryptosporidium spp. na amostra de água é influenciada pelo número de oocistos presentes, pela sensibilidade do método e pelo método de concentração dos oocistos na amostra, cujo aperfeiçoamento é fundamental para a precisão da análise e pesquisa do parasito.

Palavras-chave Cryptosporidium spp., Transmissão hídrica, Métodos de diagnósticos, Concentração de oocistos 


\section{Introdução}

A criptosporidiose é conhecida por sua ocorrência na população humana e animal, notadamente naqueles pacientes imunocomprometidos (Crawford e Vermund, 1988), pois uma vez estabelecida a infecção, a severidade do quadro clínico resulta quase sempre em óbito. No Brasil, 2.842 casos da doença foram detectados no período de 1980 a 1997 entre os pacientes imunodeprimidos, particularmente nos portadores da Sida (Síndrome da Imunodeficiência Adquirida) sendo as regiões Nordeste e Sudeste do país as áreas mais afetadas (CRT, 1997). Na cidade de Recife, a freqüência de infecção pelo Cryptosporidium parvum nesses pacientes chegou a um percentual de $21,8 \%$, sendo superior à frequiência de outros patógenos veiculados por água e/ou alimentos (Arcoverde, 2001). No entanto, o estado imunológico não está relacionado à presença da doença, uma vez que a infecção pode ocorrer em indivíduos saudáveis, os quais apresentam um quadro clínico autolimitante. Isso torna preocupante a ocorrência de portadores assintomáticos para a saúde pública. Outro ponto importante é a ausência de uma conduta terapêutica eficaz contra a criptosporidiose.

Dentre as diversas formas de transmissão da criptosporidiose, destaca-se a veiculação por água e alimentos (Smith, 1993), sendo o mecanismo de transmissão influenciado pelo nível de contaminação ambiental, sobrevivência do oocisto às condições do meio (Robertson et al., 1992), e resistência do oocisto aos mais variados métodos usados em tratamentos da água (Korich et al., 1990), seja a cloração, a ozonização ou a incompleta remoção dos oocistos pelos métodos de filtração.

Vários surtos da doença foram atribuídos ao consumo de água contaminada, sejam elas submetidas ou não ao tratamento por cloro ou outros processos tais como coagulação, sedimentação e filtração em areia (Cetesb, 2000). Um dos problemas para controlar a infecção é a escassez de dados sobre a real ocorrência de Cryptosporidium spp. em mananciais aquáticos potáveis, levando a uma subestimação de casos de criptosporidiose e muitas vezes a associação de surtos seguidos de óbito com outros patógenos, particularmente o agente etiológico da cólera. No Brasil, dados obtidos por Gamba et al. (2000) e Franco et al. (2001) mostraram a presença de oocistos em poços localizados na cidade de Itaquaquecetuba (SP) e nas águas superficiais do rio Atibaia em Campinas (SP).

A importância do estudo sobre a ocorrência de Cryptosporidium spp. no ambiente aquático foi reforçada pelas citações da portaria 1.469 do Ministério da Saúde (2000), que recomenda a inclusão da pesquisa de Cryptosporidium spp. para se atingir o padrão de potabilidade da água. Além de que os coliformes fecais, considerados referência mundial como indicador microbiológico para água e alimentos, não são bons indicadores para protozoários (Harich et al., 1999). Isso vem alertar e despertar o interesse das empresas de saneamento para o seu enquadramento na referida legislação, cujos recursos se baseiam na associação da ocorrência do parasito com parâmetros de previsibilidade, e principalmente na sua pesquisa direta em amostras de água. A escolha de um método de pesquisa a ser empregado em análise de rotina depende de alguns fatores, dentre eles o custo-benefício associado às recomendações previstas em normas oficiais para o padrão de ausência de Cryptosporidium spp.

É de extrema relevância a padronização de um eficiente método de pesquisa para Cryptosporidium spp., e a obtenção de dados de ocorrência e distribuição do parasito por região para o planejamento e estabelecimento de medidas de controle e vigilância da água para consumo humano. Além de que se faz necessário o esclarecimento sobre as espécies existentes em mananciais aquáticos, sobre os parâmetros de previsibilidade e ocorrência sazonal do parasito para uma avaliação do risco de infecção pelo Cryptosporidium na população humana.

\section{Classificação de Cryptosporidium quanto à espécie e genótipo}

O estudo filogenético vem sendo realizado por vários grupos de pesquisadores (Tzipori e Griffiths, 1998; Morgan e Thompson, 1998; Xiao et al., 1998; 1999), porém ainda há divergências quanto à taxonomia do Cryptosporidium. Desde a descoberta do C. muris e C. parvum em roedores, em torno de 20 espécies de Cryptosporidium têm sido mencionadas em várias espécies de hospedeiros animais (O'Donoghue, 1995). Tzipori et al. (1980) comentam sobre uma peculiaridade que distingue o Cryptosporidium da grande maioria dos outros coccídios, a falta de especificidade para hospedeiros. Arcay et al. (1995) reforçam essa idéia ao infectar 
todas as classes de vertebrados (mamíferos, aves, répteis, anfíbios e peixes) com o C. parvum isolado do homem, sugerindo a existência de uma única espécie.

Baseado nessas observações Levine (1984 e 1986) classificou o parasito e atualmente acredita-se que as seguintes espécies são consideradas válidas: Cryptosporidium parvum responsável por doenças clínicas em humanos e outros mamíferos; o Cryptosporidium muris encontrado em roedores e em outros mamíferos; Cryptosporidium meleagridis e Cryptosporidium baileyi que infectam aves; Cryptosporidium nasorum encontrada em peixes e Cryptosporidium serpentis em répteis (O’Donoghue, 1995). Estudos subseqüentes adicionaram à lista de espécies válidas, C. wrairi de cobaias e $C$. felis de gatos (Xiao et al., 1999).

Tzipori e Griffiths (1998) baseando-se em análises filogenéticas citam que as variações inter e intra-espécie não permitem ainda designar espécies diferentes de Cryptosporidium, e todos os oocistos do parasito, incluindo aquelas de hospedeiros vertebrados inferiores, podem ser perigosos para o homem. Recentes avanços nesse assunto indicam que há multiespécies complexas contida em pelo menos quatro espécies de Cryptosporidium: C. parvum, $C$. muris, C. baileyi e C. serpentis, enquanto as referidas espécies como C. wairi, C. felis, C. meleagridis e C. saurophilum estariam agrupadas no C. parvum (as demais espécies não foram estudadas). Assim, há vários genótipos diferentes de C. parvum (genótipo 1, genótipo 2, genótipo guinea pig, genótipo Monkey e Koala) de grande importância epidemiológica, uma vez que o genótipo 1 é a cepa responsável pela maioria das infecções humanas, enquanto o genótipo 2 provavelmente é o que mais ocorre no ambiente, podendo infectar animais e homens (Xiao et al., 1998 e 1999).

Seguindo a mesma linha de pesquisa, Koch et al. (1985) comentam que a existência de dois grandes genótipos estaria associada com os dois diferentes ciclos de transmissão, um dos quais sendo por transmissão antroponótica e o outro por transmissão zoonótica e significativamente do bovino ao homem. Gibbons et al. (1998), através de estudos de tipificação molecular, identificaram genótipos humano e animal, designados de genótipo $\mathrm{H}$ (Human) e genótipo C (Calf), respectivamente (Morgan e Thompson, 1998).

A freqüência de infecção pelo Cryptosporidium na população humana tem sido bem es- tudada e divulgada documentando-se a infecção pelo C. parvum. No entanto Katsumata et al. (2000) revelaram a suspeita de infecção no homem pelo C. muris. Esse fato é bastante relevante para alertar sobre a importância da precisão no diagnóstico da infecção quanto à diferenciação entre as espécies, seja morfológica (Upton e Current, 1985) ou geneticamente, uma vez que a caracterização do Cryptosporidium pela biologia molecular tem evoluído bastante.

\section{Veiculação de Cryptosporidium spp. por água}

A presença de oocistos de Cryptosporidium spp. nos mananciais aumenta a preocupação com a transmissão do parasito, porque enquanto ocorre por contato com fômites contaminados, de pessoa a pessoa, animal a pessoa, restringese o número de pessoas infectadas, no entanto quando ocorre por veiculação hídrica pode atingir facilmente um grande contingente da população. Smith (1998) descreve sobre as diversas razões para Giardia spp. e Cryptosporidium spp. tornarem-se significantes patógenos de transmissão hídrica: provocam infecções endógenas com baixa dose infectante, as densidades de contaminação ambiental com cistos e oocistos infectantes são suficientes para poluir o ambiente aquático, e os oocistos são bastante pequenos para atravessar o processo de tratamento da água além de serem resistentes aos desinfetantes comumente empregados no tratamento da água.

O primeiro surto de criptosporidiose, que vitimou 79 pessoas, ocorreu em 1984 no Texas (EUA), sendo diagnosticado por um estudo epidemiológico, portanto sem a confirmação do parasito na água de poço suspeita. A partir deste outros casos foram descritos, e dentre aqueles de maior impacto estão os casos que ocorreram na Geórgia (EUA) em 1987, onde 13.000 pessoas foram afetadas, e em Saitama (Japão), em 1996, quando 8.705 indivíduos foram acometidos, sendo o Cryptosporidium detectado na água tratada e não-tratada. Em Oregon (EUA) houve 15.000 casos de criptosporidiose e o parasito foi detectado na água em processo de tratamento, enquanto em Milwaukee e Wisconsin (EUA), em 1993, o Cryptosporidium encontrado na água de gelo infectou 403.000 pessoas. Dentre as fontes de contaminação das águas destaca-se a contaminação 
cruzada de águas de poço ou encanada por água de esgoto, falha nos procedimentos operacionais, desvios do filtro de areia, contaminação de águas superficiais por esterco bovino, e influências de efluentes industriais e agrícolas nas águas de recreação (Smith, 1998).

A ocorrência de Cryptosporidium spp. no ambiente aquático tem sido verificada em vários países. Amostras de água não-tratada e tratada foram avaliadas quanto à ocorrência do Cryptosporidium spp. em 66 estações de tratamento de água de 14 estados e uma província do Canadá. Quanto à positividade das amostras da água não-tratada pode-se observar que 97\% (82 de 85 ) das amostras coletadas de diversos pontos nas 66 estações foram positivas para o parasito, com um número médio de oocistos de 2,7 por litro, porém com uma variação de 0,07 a 484 oocistos por litro. Esse resultado revelou um percentual de positividade de $87 \%$ do total das estações avaliadas. $\mathrm{Na}$ água tratada, diante de 82 amostras analisadas, em $22 \%$ foi detectado o Cryptosporidium spp. com um número médio de 1,52 oocistos por litro (LeChevallier et al., 1991). Uma ampla variação no número de oocistos nas amostras de água também foi verificada por Ongerth e Stibbs (1987) quando pesquisaram o Cryptosporidium nas águas de rio em Washington e na Califórnia, pois o parasito foi encontrado em todas as amostras variando de 2 a 112 oocistos por litro. Na Costa Rica 14 amostras de águas superficiais foram analisadas, sendo sete de água bruta e sete de água tratada sem cloração, e verificou-se que o parasito estava presente em $85,7 \%$ das amostras de água não-tratada e em $57 \%$ das amostras de água tratada (Luna et al., 2002).

Quanto à pesquisa de Cryptosporidium spp. em amostras de água no Brasil os estudos são recentes, mas alguns trabalhos já foram realizados no Estado de São Paulo, de forma que o parasito já foi detectado em águas superficiais e profundas. A identificação de oocistos de Cryptosporidium spp. nas águas do rio Atibaia em Campinas e a alta turbidez das amostras foram justificadas pelas intensas chuvas no período (Franco et al. 2001). Em águas de poço da cidade de Itaquaquecetuba (SP) a presença de oocistos pode ter sido resultante de influências da superfície externa, pois havia possibilidade de infiltrações, pelo grande número de animais nas redondezas, além da possibilidade de contaminação cruzada com águas oriundas de fossas sépticas, as quais também apresenta- vam o parasito (Gamba et al. 2000). Na cidade de São Paulo analisando 24 amostras de esgotos, Farias et al. (2002) verificaram que o Cryptosporidium estava presente em todas as amostras variando de 80 a 912 oocistos por litro no esgoto doméstico e de 65 a 760 oocistos quando a pesquisa foi feita no córrego.

No que se refere ao tratamento da água, comparando-se a filtração em que se utiliza o filtro de areia, a filtração dupla ou a filtração mista, LeChevallier et al. (1991) observaram que o número de amostras positivas para os oocistos de Cryptosporidium spp. é maior quando se emprega o tratamento com o filtro de areia, e que o problema com a filtração está associado ao tamanho dos oocistos de Cryptosporidium spp., que varia de 3 a $6 \mu \mathrm{m}$, de forma que atravessa facilmente as barreiras no processo de filtração, principalmente quando encontra-se em grande número na água não-tratada. As plantas de filtração com carvão ativado são freqüentemente usadas quando a qualidade da água é muito precária, e LeChevallier et al. (1991) demonstraram que mais de $60 \%$ dos efluentes filtrados por essa planta apresentaram oocistos de Cryptosporidium spp., superior às plantas de tratamento em que se usa o filtro de areia, nas quais as amostras positivas dos efluentes filtrados superaram o valor de $36 \%$. Assim verifica-se que pode haver redução do número de oocistos nas águas superficiais com o tratamento pelo processo de filtração, porém há influência quanto ao tipo de tratamento simples, duplo ou misto, e quanto ao tipo de filtro utilizado.

\section{Parâmetros de previsibilidade para oocistos de Cryptosporidium spp.}

A comparação entre os parâmetros de qualidade da água com a presença de Cryptosporidium $s p p$. é um subsídio para prever a sua ocorrência no ambiente aquático e com isso orientar quanto à performance dos tratamentos empregados e aos procedimentos preventivos. Dentre os fatores envolvidos na mensuração da qualidade da água, a turbidez é um importante parâmetro, pois devido à facilidade de aderência dos oocistos de Cryptosporidium spp. a compostos orgânicos e inorgânicos (Medema et al., 1998) a sua presença tem sido associada ao grau de turbidez da amostra, de forma que quanto maior o grau de turbidez na amostra de água, maior a possibilidade de se encontrar o parasi- 
to, tanto na água não-tratada como na água tratada. De acordo com a portaria 1.469 (Ministério da Saúde, 2000), para garantir a qualidade microbiológica da água deve-se ter turbidez máxima de 1,0 UT em 95\% das amostras analisadas após o processo de filtração rápida, mas no que se refere à remoção de Cryptosporidium spp. é recomendado um valor máximo de 0,5 UT para o grau de turbidez. No entanto tem-se observado que os oocistos ainda ocorrem quando a turbidez encontra-se com o valor de 0,19 UT, de forma que a garantia de efetiva segurança seria obtida com a turbidez de 0,1 UT (LeChevallier et al., 1991).

Outro parâmetro relevante que tem sido associado com a ocorrência de Cryptosporidium spp. é a determinação dos coliformes. LeChevallier et al. (1991) demonstraram uma correlação positiva entre a ocorrência de coliformes e de Cryptosporidium spp., porém o fato não está bem elucidado na literatura, e autores têm demonstrado o contrário (Gamba et al., 2000; Shepherd \& Jones, 1996; Silva, 2002).

Tem-se observado que a pesquisa do parasito em animais marinhos é uma forma indireta de se verificar a presença de oocistos de Cryptosporidium spp. em águas de estuários, de forma que a presença do oocisto em ostras tem demonstrado o seu potencial como monitor biológico para a contaminação da água pelo parasito, além de servir como um filtro natural (Xiao et al., 1998). Outras espécies de moluscos bivalves como mexilhões e mariscos têm apresentado positividade e grande acúmulo de oocistos de Cryptosporidium spp. em seu organismo (Freire-Santos et al., 2000). Recentemente, o parasito foi diagnosticado em peixe-boi marinho (Marcondes et al., 2002).

\section{Métodos de análises para a detecção de oocistos de Cryptosporidium spp.}

Diferentes métodos de diagnóstico têm sido desenvolvidos para a detecção de Cryptosporidium spp. em amostras de água, cada qual com suas vantagens e desvantagens, porém ainda não há um método universalmente aceito (Smith, 1998). Os métodos utilizados em amostras de água têm sido os mesmos empregados em análises clínicas, mas a maior preocupação com o procedimento de análise é que, previamente ao método de identificação do parasito, é necessário empregar um método de concentração satisfatório, porque apesar da existência de métodos de identificação sofisticados para a pesquisa de oocistos de Cryptosporidium spp. como a biologia molecular, todos são precedidos de métodos para a concentração dos oocistos na amostra.

Os métodos empregados para a análise de amostras de água se subdividem em filtração, eluição, concentração com ou sem purificação, e identificação (Smith, 1998). A filtração pode ser considerada uma etapa para extração do oocisto (Nieminski et al., 1995) ou para concentração (Barer e Wright, 1990). Segundo Laberge et al. (1996) em análise de um grande volume de água torna-se necessário a utilização das etapas de filtração e eluição utilizando membranas (Aldom e Chagla, 1995) ou filtros (Kaucner e Stinear, 1998), porém quando se analisa um pequeno volume, essas etapas podem ser omitidas partindo direto para a etapa de concentração por centrifugação (Ongerth e Stibbs, 1987) ou por floculação (Vesey et al., 1993a).

Para o isolamento a extração do oocisto de Cryptosporidium spp. em amostras de água, previamente à concentração por centrifugação das amostras, diferentes métodos têm sido desenvolvidos e dentre eles a filtração em membrana e a floculação com carbonato de cálcio, sendo ainda subestimada a sua eficiência (Vesey et al., 1993a). A técnica de filtração em membrana foi originalmente desenvolvida para ser aplicada em água tratada (Aldom e Chagla, 1995), no entanto tem sido particularmente útil para uma rápida determinação do número de oocistos em água não-tratada (Dawson et al., 1993). O método de floculação tem sido empregado por ser simples e econômico e por analisar um pequeno volume de água (Vesey et al., 1993a), porém a elevada concentração dos resíduos junto aos oocistos pode afetar a interpretação dos resultados.

Segundo Farias et al. (2002), a compactação das partículas com a filtração em membrana é de difícil desagregação, e oocistos podem ser perdidos quando se utiliza procedimentos de centrifugação com gradientes de densidades para clarificar a amostra, enquanto no método de floculação embora haja formação de partículas maiores, estas são menos compactadas do que as partículas obtidas por filtração, no entanto recomendam que outros estudos são necessários para aprimorar o método e determinar sua performance, antes de ser rotineiramente usado. 


\section{Métodos de concentração}

Em alimentos e em amostras de água tratada ou ambiental os oocistos de Cryptosporidium $s p p$. podem ser encontrados em baixo número tornando-se importante a seleção dos métodos de concentração da amostra, pois ainda é inexistente a técnica que possibilita um enriquecimento para esse organismo semelhante às bactérias alertando para a utilização de métodos altamente sensíveis (Laberge et al., 1996).

A concentração de oocistos de Cryptosporidium spp. por centrifugação tem sido realizada em amostras de água (LeChevallier et al., 1995; Nieminski et al., 1995), associando etapas de sedimentação com uma etapa de flutuação, sendo a pesquisa do oocisto feita em sua maioria no sedimento obtido de uma centrifugação em que foi usado o volume sobrenadante resultante da etapa anterior de flutuação, que por sua vez é realizada a partir do sedimento concentrado.

É importante salientar que as substâncias utilizadas para concentração de oocistos com densidades entre 1,050 e 1,300, através de gradientes de densidades contínuos ou descontínuos, são empregadas com a finalidade de flutuação e clarificação das amostras (Deng \& Cliver, 1999; 2000; Kuczynska \& Shelton, 1999; LeChevallier et al., 1995).

Smith (1998) comenta que as soluções normalmente usadas para flutuação de oocistos são soluções saturadas de sacarose com densidade entre 1,100 e 1,200, porém tem sido empregada a solução Sheather com densidade de 1,200 (Deng \& Cliver, 1999), $\mathrm{MgSO}_{4}$ (densidade específica de 1,270), $\mathrm{ZnSO}_{4}$ (densidade específica de 1,300), e $\mathrm{NaCl}$ (densidade específica de 1,210) conforme Kuczynska \& Shelton (1999) para gradientes contínuos e a solução Percoll-sacarose com densidade entre 1,050 a 1,100 (Nieminski et al., 1995), Percoll $(1,130$, $1,090,1,050$ e 1,010$), \mathrm{CsCl}(1,400,1,100$ e 1,050) de acordo com Kuczynska \& Shelton (1999) para gradientes descontínuos.

A centrífugo-flutuação tem a finalidade de separar cistos ou oocistos de protozoários de resíduos sólidos na amostra e, quando realiza$\mathrm{da}$, os oocistos na amostra devem ser previamente concentrados por sedimentação através de várias lavagens na ausência do líquido flutuante para se obter um sedimento (Smith, 1998). LeChevallier et al. (1995) comentam que a gravidade específica do gradiente é escolhida para que os microrganismos flutuem em sua superfície e para que os resíduos mais pesados sedimentem.

Nieminski et al. (1995), pesquisando influências na recuperação dos oocistos em amostras de água (água de abastecimento, água pré-tratada por floculação e água filtrada), observaram que os melhores resultados foram provenientes da análise do sedimento obtido previamente à etapa de flutuação, ao pesquisar os oocistos direto da membrana filtrante após a sua eluição e concentração, detectando um valor de recuperação de $78 \%$. Quando a etapa de flutuação foi empregada pelos autores houve redução de mais de 50\% do número de oocistos recuperados, e verificaram que quanto menor o número de etapas no procedimento, menor a probabilidade de perdas de oocistos.

Vesey et al. (1993a) realizaram a concentração de oocistos em amostras de água apenas por sedimentação, e objetivando avaliar a eficiência na recuperação de oocistos de Cryptosporidium spp. em água desenvolveram um método de floculação por decantação de cristais de carbonato de cálcio $\left(\mathrm{CaCO}_{3}\right)$ após a mistura de cloreto de cálcio $\left(\mathrm{CaCl}_{2}\right)$, bicarbonato de sódio $\left(\mathrm{NaHCO}_{3}\right)$ e hidróxido de sódio $(\mathrm{NaOH})$ em $1 \mathrm{~L}$ de amostra inoculada com 608 oocistos, a qual foi submetida a um repouso de 4 horas. Os cristais de $\mathrm{CaCO}_{3}$ sedimentados foram dissolvidos em ácido sulfâmico, resultando em percentual de recuperação de 73,7\%, 75,6 e $76 \%$ para água de abastecimento, água de rio e água deionizada, respectivamente.

LeChevallier et al. (1991) relataram que vários fatores interferem na eficiência de recuperação de oocistos em água por processos de concentração por sedimentação ou flutuação, dentre eles a variação da densidade do oocisto, pois oocistos de baixa densidade provavelmente serão menos recuperados por técnicas de sedimentação e os oocistos de maior densidade serão menos eficientemente recuperados por técnica de flutuação.

Segundo Medema et al. (1998) desde que o meio de flutuação tenha densidade entre 1,090 e 1,100 provavelmente resultará em perdas insignificantes porque $95 \%$ dos oocistos têm densidade menor que 1,090 , sendo a densidade média de 1,045.4 verificada para os oocistos de Cryptosporidium spp.

Lima (2001), comparando diversas substâncias (sacarose-densidade de 1,065, NaCldensidade de 1,155, MgSO4-densidade de 1,300, ZnSO4-densidade de 1,200, AlSOA-densidade de 1,115, NH4SO4 40\%-densidade de 
1,115 e NH4SO4 80\%-densidade de 1,200) para a concentração de oocistos de Cryptosporidium spp. nas amostras de água e leite, verificou que a eficácia dos métodos de detecção desse parasito depende da natureza da amostra e da substância para a sua concentração, e observou que nas amostras de água o cloreto de sódio proporcionou uma melhor concentração e recuperação de oocistos, porém com a sedimentação de todos os oocistos.

A densidade do oocisto pode ser alterada devido a sua facilidade de aderência a outras partículas. Medema et al. (1998) comentam que é mais alta a proporção de oocistos de Cryptosporidium spp. em águas superficiais aderido às partículas como lodo, areia, plâncton, algas e cristais biológicos. Nieminski et al. (1995) relatam que a variação na eficiência de recuperação dos oocistos de Cryptosporidium spp. em amostras de água por centrífugo-flutuação deve-se à presença de algas e cristais químicos. Kuczynska \& Shelton (1999) descrevem sobre a aderência dos oocistos de Cryptosporidium spp. em sólidos fecais, e comentam que a análise de amostras fecais estocadas pode subestimar os níveis do porcentual de recuperação dependendo do grau de oocistos aderidos aos sólidos fecais e que experimentalmente a análise da amostra deve ser realizada logo após a sua inoculação com a suspensão de oocistos previamente purificada.

Segundo Smith e Rose (1990) a interação não-covalente entre a superfície negativamente carregada do oocisto e outras partículas na matriz é reduzida pela adição de soluções detergentes como tween 20, tween 80 e duodecil sulfato de sódio que reduzem agregações e mantêm os oocistos como organismos individuais. LeChevalier et al. (1995) verificaram que a ausência de soluções detergentes para a concentração por flutuação por Percoll-sacarose das amostras de água de abastecimento não interferiu nos resultados, alcançando $100 \%$ de recuperação quando se utilizou Percoll-sacarose com densidade igual a 1,150, e apesar de utilizarem um inóculo sem prévia purificação para contaminação das amostras, este foi preparado com amostra fecal recente e imediatamente anterior às análises. A probabilidade de adesão particularmente depende da característica superficial do oocisto que pode ser por alteração devido aos procedimentos de purificação e estocagem (Medema et al., 1998).

\section{Métodos de identificação}

Devido à ausência de técnicas específicas para a detecção de Cryptosporidium spp. em água e alimentos, as análises têm sido realizadas por adaptação da metodologia empregada para análises clínicas. Smith et al. (1989) analisaram amostras de água in natura, filtrada e tratada utilizando um inóculo contendo $10^{3}$ oocistos de Cryptosporidium spp. por mililitro ( $\mathrm{ml}$ ) previamente purificado e armazenado a $4{ }^{\circ} \mathrm{C}$ por dois meses. As amostras contaminadas foram armazenadas a $4^{\circ} \mathrm{C}$ por duas semanas para posterior concentração por solução descontínua de sacarose. Para a identificação dos oocistos foram comparados os métodos de coloração histoquímica (Ziehl-Nielsen, auramina-fenol, Giemsa e safranina-azul de metileno) e imunofluorescência indireta com anticorpo monoclonal (FITC-Mab). Verificaram que os métodos de Ziehl-Nielsen e FITC-Mab foram os melhores na identificação dos oocistos, proporcionando recuperação de números elevados e semelhantes ( $86 \%$ e $87 \%$, respectivamente), considerando os valores-teste da amostra-controle entre 71 e $89 \%$ de recuperação.

Outras técnicas têm sido descritas para a detecção de Cryptosporidium spp. em amostras de água incluindo o método de Koster modificado (Luna et al., 2002), a citometria de fluxo (Vesey et al., 1993b) e a reação em cadeia de polimerase - PCR (Kaucner e Stinear, 1998). Kaucner \& Stinear (1998) comentam que a vantagem do PCR é a rapidez, sensibilidade e especificidade, tornando um método de diagnóstico seguro, uma vez que se baseia na amplificação e subseqüente detecção de seqüências específicas do DNA do parasito. Segundo Taylor e Webster (1998), os métodos empregados para a identificação do agente diferem quanto à sensibilidade, sendo o limite de detecção maior que 50 oocistos por litro para o método de imunofluorescência, maior que 100 para o método histoquímico e menor que 100 para o PCR.

\section{Fatores que influenciam na detecção e recuperação dos oocistos de Cryptosporidium spp.}

A recuperação experimental de oocistos de Cryptosporidium spp. depende da natureza e do tipo de amostra, do tipo de substâncias de concentração e ainda da metodologia para concentração e identificação do oocisto (Vesey et al., 
1993a; Nieminski et al., 1995; LeChevallier et al., 1995). Isso reflete e ao mesmo tempo esclarece a possibilidade de variação nos dados a serem obtidos e vem auxiliar na seleção adequada do método de análise para a pesquisa de Cryptosporidium spp.

Nas amostras de água deve-se considerar a turbidez, principalmente no que se refere ao grau de impureza inorgânica (química) conforme Nieminski et al. (1995) ou orgânica (biológica) segundo Medema et al. (1998). Nas amostras de alimentos, a influência pode ser observada pela composição da amostra (Smith \& Rose, 1990; Deng \& Cliver, 1999; 2000). Quanto às amostras fecais deve-se observar se essas são recentes ou conservadas, seja à temperatura ambiente ou sob refrigeração (Kuczynska \& Shelton, 1999; Smith et al., 1989). Estas considerações são justificadas pela facilidade de aderência dos oocistos e por isso a importância de se atentar para o tempo que os oocistos ficam em contato com as partículas na amostra (LeChevallier et al., 1995).

Quanto às substâncias de concentração, a influência é verificada pela sua densidade e característica físico-química geral, pois, de acordo com a densidade e composição das amostras analisadas, podem influenciar apenas na densidade do meio, mas também provocar aglomeração ou dispersão das partículas resultando na dualidade entre a flutuação ou sedimentação das partículas presentes (Kuczynska \& Shelton, 1999; Vesey et al., 1993a).

Kuczynska \& Shelton (1999) avaliando substâncias de concentração sugerem que a alta recuperação com o $\mathrm{NaCl}$ para flutuação pode ter sido devido à habilidade de cátions monovalentes em dispersar partículas permitindo a separação dos oocistos com os resíduos. Enquanto o baixo número obtido com a solução de flutuação de $\mathrm{ZnSO}_{4}$ pode ter sido resultante da ação dos cátions divalentes em precipitar as partículas e agregar os oocistos levando a sedimentação de todos presentes. Em relação à solução de sacarose, a baixa recuperação observada foi provavelmente devido ao seu baixo peso específico e a alta viscosidade da solução.

Bukhari e Smith (1995) acrescentam que o grau de recuperação de oocistos através de substâncias de concentração depende de sua influência na viabilidade dos oocistos, pois avaliando três técnicas de concentração para recuperação de oocistos de Cryptosporidium parvum de fezes bovina observaram que a concentração por sedimentação com água-éter não exerceu significante efeito na viabilidade dos oocistos recuperados, porém o gradiente de flutuação com sacarose ou sulfato de zinco seletivamente concentraram oocistos viáveis, de forma que a superfície dos oocistos não viáveis é mais susceptível à adesão aos sólidos fecais e, conseqüentemente, sedimentam juntos. No entanto LeChevalier et al. (1995) observaram que após o armazenamento de oocistos em água de rio na temperatura ambiente por 30 dias para o seu envelhecimento, muitos organismos morreram e tornaram-se células vazias favorecendo uma maior eficiência de recuperação comparado aos organismos recentes, sugerindo que oocistos vazios são preferivelmente concentrados por flutuação em gradiente de Percoll-sacarose.

De um modo geral, a recuperação ou detecção de oocistos por determinados métodos ou substâncias de concentração através da pesquisa destes oocistos nos sedimentos pode resultar em uma subestimação dos resultados se os oocistos flutuam ou contrariamente quando a pesquisa é feita apenas no sobrenadante e os oocistos sedimentam (LeChevallier et al., 1991). Os resultados ainda podem ser dúbios devido à associação de um determinado procedimento de análise com um dos métodos de identificação, quando a especificidade do método depende da integridade do oocisto (Vesey et al., 1993a).

Segundo Ongerth \& Stibbs (1987) e LeChevallier et al. (1991) a natureza abrasiva dos métodos pode causar danos ao oocisto e levar à perda de epitopos que são necessários para a sua deteç̧ão pelos anticorpos monoclonais ou tendem a compactar outras partículas ao oocisto ou ao seu redor que causam futuros problemas no estágio de detecção.

Segundo Bukhari et al. (1998), o procedimento de concentração provoca um acúmulo de resíduos na amostra de água sendo necessário o procedimento de clarificação para separálos dos oocistos e permitir a sua detecção, porém o grau de purificação pode ser variável e o material flutuante pode conter, além de oocistos, inúmeras partículas e células de algas que interferem na identificação dos oocistos por imunofluorescência.

Conforme Vesey et al. (1993a), um agregado de partículas pode causar um bloqueio quando se utiliza a citometria de fluxo para o diagnóstico de Cryptosporidium, salientandose que é difícil a desagregação dessas partículas compactadas. 


\section{Considerações finais}

Os estudos com a metodologia para a pesquisa de Cryptosporidium spp. em amostras de água vêm sugerindo mecanismos alternativos para a otimização dos métodos, e isso é imprescindível uma vez que a legislação atual, referente às normas de qualidade da água para consumo humano, recomenda o padrão de ausência para oocistos de Cryptosporidium spp., de forma que há a necessidade de uma técnica com limi-

\section{Referências bibliográficas}

Aldom JE \& Chagla AH 1995. Recovery of Cryptosporidium oocysts from water by a membrane filter dissolution method. Letters in Applied Microbiology 20:186187.

Arcay L, DeBorges EB \& Bruzual 1995. Criptosporidiosis experimental en la escala de vertebrados, I. Infecciones experimentales, II. Estudio histopatológico. Parasilogia al Dia 19:20-29.

Arcoverde CAC 2001. Enteroparasitoses em pacientes infectados com o Virus da Imunodeficiência Humana (HIV) atendidos no Hospital das Clínicas da UFPE. Dissertação de mestrado, Universidade Federal de Pernambuco, Recife/.

Barer MR \& Wright AE 1990. Cryptosporidium and water: a review. Letters in Applied Microbiology 11:271277.

Bukhari Z \& Smith HV 1995. Effect of three concentration techniques on viability of Cryptosporidium parvum oocysts recovered from bovine feces. Journal of Clinical Microbiology 33(10):2.592-2.595.

Bukhari Z, McCuin RM, Fricker CR \& Clancy JL 1998. Immunomagnetic separation of Cryptosporidium parvum from source water samples of various turbidities. Applied and Environmental Microbiology 64(11):4.495-4.499.

Centro de Referência e Treinamento 1997. Doenças Sexualmente Transmissiveis/Aids (CRT-DST/AIDS), São Paulo.

Cetesb 2000. Microbiologia ambiental (Norma Técnica L5.), São Paulo.

Crawford FG \& Vermund SH 1988. Human Cryptosporidiosis. Critical Review of Microbiology 16:113159.

Dawson DJ, Maddocks M, Roberts J \& Widler JS 1993. Evaluation of recovery of Cryptosporidium parvum oocysts using membrane filtration. Letters in Applied Microbiology 17:276-279.

Deng MQ \& Cliver DO 1999. Cryptosporidium parvum studies with dairy products. International Journal of Food Microbiology 46:113-121.

Deng MQ \& Cliver DO 2000. Comparative detection of Cryptosporidium parvum from apple juice. International Journal of Food Microbiology 54:155-162. te de detecção de um oocisto por litro. A técnica de biologia molecular tem sido avaliada e o seu desempenho na identificação de espécies de Cryptosporidium e na diferenciação entre os genótipos do C. parvum pode auxiliar na investigação dos casos clínicos da criptosporidiose, enquanto a performance dessa técnica na análise de amostras ambientais poderá ser útil no monitoramento da ocorrência de Cryptosporidium spp. em baixo número.
Farias EWC, Gamba RC \& Pellizari VH 2002. Detection of Cryptosporidium spp. Oocysts in raw sewage and creek water in the city of São Paulo, Brazil. Brazilian Journal of Microbiology 33(1):41-43.

Franco RMB, Rocha-Eberhardt R \& Cantusio Neto R 2001. Occurrence of Cryptosporidium oocysts and Giardia cysts in raw water from the Atibaia river, Campinas, Brazil. Revista do Instituto de Medicina Tropical de São Paulo 42(2):109-111.

Freire-Santos F et al. 2000. Detection of Cryptosporidium oocysts in bivalve mollusks destined for human consumption. Journal of Parasitology 86(4):853-854.

Gamba RC, Ciapina EM, Espindola RS, Pacheco A \& Pellizari VH 2000. Detection of Cryptosporidium sp. Oocysts in groundwater for human consumption in Itaquaquecetuba city, São Paulo-Brazil. Brazilian Journal of Microbiology 31:151-153.

Gibbons CL et al. 1998. Correlation between markers of strain variation in Cryptosporidium parvum: evidence of clonaty. Parasitology International 47:139147.

Harich et al. 1999. Deteç̧ão de oocistos de Giardia e oocistos de Cryptosporidium em águas superficiais captadas para consumo humano. XX Congresso Brasileiro de Microbiologia, Salvador.

Katsumata T et al. 2000. Short report: Cryptosporidium muris infection in humans. The American Journal of Tropical Medicine and Hygiene 62(1):70-72.

Kaucner C \& Stinear T 1998. Sensivite and rapid detection of Giardia cysts and Cryptosporidium parvum oocysts in large-volume water samples with wound fiberglass cartridge filters and reverse transcription PCR. Applied and Environmental Microbiology 64 (5):1.743-1.749.

Koch KL, Phillips DJ, Aber RC \& Current WL 1985. Cryptosporidiosis in hospital personnel: evidence for person-to-person transmission. Annals Internal Medicine 102:593-596.

Korich DG, Mead JR, Madore MS, Sinclair NA \& Sterling CR 1990. Effect of ozone, chlorine dioxide, chlorine and monochloroamine on Cryptosporidium oocyits viability. Applied and Environmental Microbiology 56: 1.423-1.428. 
Kuczynska E \& Shelton DR 1999. Method for detection and enumeration of Cryptosporidium parvum oocysts in feces, manures, and soils. Applied and Environmental Microbiology 65(7):2.820-2.826.

Laberge I \& Griffiths MW 1996. Prevalence, deteccion and control of Cryptosporidium parvum in food. International Journal of Food Microbiology 31:1-26.

LeChevallier MW, Norton WD \& Lee RG 1991. Ocurrence of Giardia and Cryptosporidium spp. in surface water supplies. Applied and Environmental Microbiology 57(9):2.610-2.616.

LeChevallier MW, Norton WD, Siegel JE \& Abbaszadegan M 1995. Evaluation of the immunofluorescence procedure for detection of Giardia cysts and Cryptosporidium oocysts in water. Applied and Environmental Microbiology 61(2):690-697.

Levine ND 1984. Taxonomy and review of the coccidian genus Cryptosporidium (Protozoa, Apicomplexa). Journal of Protozoology 31:94-98.

Levine ND 1986. Taxonomy of Sarcocystis (Protozoa, Apicomplexa) species. Journal of Parasitology 72:372382.

Lima EC 2001. Métodos de deteç̧ão e enumeração de oocistos de Cryptosporidium spp. em amostras de água e leite. Dissertação de mestrado. Universidade Federal de Pernambuco, Recife.

Lima EC et al. 2001. Importância da criptosporidiose para a saúde pública. Revista Ciência Veterinária no Trópicos 4(1):229-239.

Luna S, Liliana Reyes L, Chincgilla M \& Catarinella G 2002. Presencia de ooquistes de Cryptosporidium spp en aguas superficiales en Costa Rica. Parasitologia Latinoamericana 57:63-65.

Marcondes MCC et al. 2002. Cryptosporidium spp. in Antillian Manattees (Trichechus manatus manatus) in natural captivity, Paraíba State, Brazil. Florida Marine Mammal Health Conference, April 4-7, Gainesville, Flórida.

Medema GJ, Schets FM, Teunis PFM \& Havelaar H 1998. Sedimentation of free and attached Cryptosporidium oocysts and Giardia cysts in water. Applied and Environmental Microbiology 64(11):4.460-4.466.

Ministério da Saúde 2000. Portaria 1.469 de 29 de dezembro de 2000, republicada no D. O.U. no $38-\mathrm{E}$ de 22/2/2001, Seção 1, p. 39. Funasa.

Morgan UM \& Thompson RCA 1998. PCR detection of Cryptosporidium, the way forward? Parasitology Today 14: 241-245.

Nieminski EC, Schaefer FWIII \& Ongerth JE 1995. Comparison of two methods of Giardia cysts and Cryptosporidium oocysts in water. Applied and Environmental Microbiology 61(5):1.714-1.719.

O'Donoghue PJ 1995. Cryptosporidium and criptosporidiosis in man and animals. International Journal of Parasitology 25:139-195.

Ongerth JE \& Stibbs HH 1987. Identification of Cryptosporidium oocysts in river water. Applied and Environmental Microbiology 53(4):672-676.

Ortega YR et al. 1997. Isolation of Cryptosporidium parvum and Cyclospora cayetanensis from vegetables collected in markets of an endemic region in Peru. The American Journal of Tropical Medicine and Hygiene 57(6):683-686.
Robertson LJ, Campbell AT \& Smith HV 1992. Survival of Cryptosporidium parvum oocysts under various environmental pressures. Applied and Environmental Microbiology 58:3.494-3.500.

Shepherd KM \& Win-Jones AP 1996. An evaluation of methods for the simultaneous detection of Cryptosporidium oocysts and Giardia cysts from water. Apllied and Environmentel Microbiology 62:1.3171.322 .

Silva CGM 2002. Detecção de enteroparasitas em hortaliças. Dissertação de mestrado. Universidade Federal de Pernambuco, Recife.

Smith HV, McDiarmid A, Smith AL, Hinson AR \& Gilmour RA 1989. An analysis of staining methods for the detection of Cryptosporidium spp. Oocysts in water-related samples. Parasitology 99:323-327.

Smith HV 1998. Detection of parasites in the environmental. Parasitology 117: S113-141.

Smith HV \& Rose JB 1990. Waterborne cryptosporidiosis. Parasitology Today 6:8-12.

Smith JL 1993. Cryptosporidium and Giardia as agents of foodborne disease. Journal of Food Protection 56 (5): 451-461.

Taylor MA \& Webster KA 1998. Recent advances in the diagnosis in livestock of Cryptosporidium, Toxoplas$m a$, Giardia and other protozoa of veterinary importance. Research and Veterinaria Science 65:183-193.

Tzipori S, Angus KW, Campbell I \& Gray EW 1980. Cryptosporidium: evidence for a single-species genus. Infectology and Immunity 30:884-886.

Tzipori S \& Griffiths JK 1998. Natural history and biology of Cryptosporidium parvum. Advanced Parasitology 40:5-36.

Upton SJ \& Current WL 1985. The species of Cryptosporidium (Apicomplexa: Cryptosporidiidae) infecting mammals. Journal of Parasitology 71:625-629.

Vesey G, Slade JS, Byrne M, Shepherd K \& Fricker CR 1993a. A new method for the concentration of Cryptosporidium oocysts from water. Journal of Apllied Bacteriology 75:82-86.

Vesey G, Slade JS, Byrne M, Shepherd K, Dennis PJ, Fricker CR 1993b. Routine monitoring of Cryptospporidium oocysts in water using flow citometry. Journal of Apllied G, Tchack L, Spano F \& Tzipori S 1998. A study of Cryptosporidium parvum genotypes and population structure. Memórias do Instituto Oswaldo Cruz 93(5):685-686.

Xiao L, Sulaiman I, Fayer R \& Lal AA 1998. Species and strain-specific typing of Cryptosporidium parasites in clinical and environmental samples. Memórias do Instituto Oswaldo Cruz 93(5):687-692.

Xiao L, Limor J, Sulaiman IM, Arrowood MJ \& Lal AA 1999. Diferentiation of Cryptosporidium species, strains and isolates. American Society of Medicine and Hygiene 61(3).

Artigo apresentado em 1ㅇ/4/2003

Aprovado em 5/5/2003

Versão final apresentada em 8/7/2003 